\title{
Are There Sex Differences in Knee Cartilage Composition and Walking Mechanics in Healthy and Osteoarthritis Populations?
}

\author{
Deepak Kumar PT, PhD, Richard B. Souza PT, PhD, Karupppasamy Subburaj PhD, \\ Toran D. MacLeod PT, PhD, Justin Singh BS, Nathaniel E. Calixto BS, \\ Lorenzo Nardo MD, Thomas M. Link MD, Xiaojuan Li PhD, \\ Nancy E. Lane MD, Sharmila Majumdar PhD
}

Published online: 26 February 2015

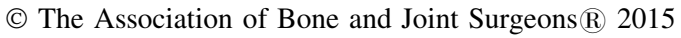

\begin{abstract}
Background Women are at a greater risk for knee osteoarthritis (OA), but reasons for this greater risk in women are not well understood. It may be possible that differences in cartilage composition and walking mechanics are related to greater OA risk in women.
\end{abstract}

This work was supported in part through funding by University of California, San Francisco, Department of Radiology Seed Grant \# 1107 and Seed Grant \# 10-04, NIH-NIAMS R01 AR046905, R01 AR062370, and NIH-NIAMS P50 063043 to NEL.

All ICMJE Conflict of Interest Forms for authors and Clinical Orthopaedics and Related Research ${ }^{\mathbb{R}}$ editors and board members are on file with the publication and can be viewed on request. Clinical Orthopaedics and Related Research ${ }^{\circledR}$ neither advocates nor endorses the use of any treatment, drug, or device. Readers are encouraged to always seek additional information, including FDA-approval status, of any drug or device prior to clinical use. This work was performed at the University of California-San Francisco, San Francisco, CA, USA.

The content is solely the responsibility of the authors and does not necessarily represent the official views of the National Institutes of Health.

D. Kumar, R. B. Souza, K. Subburaj, T. D. MacLeod, J. Singh, N. E. Calixto, L. Nardo, T. M. Link, X. Li, S. Majumdar Musculoskeletal Quantitative Imaging Research Group, Department of Radiology and Biomedical Imaging, University of California-San Francisco, San Francisco, CA, USA

D. Kumar $(\bowtie)$

Division of Physical Therapy, Department of Health Professions, Medical University of South Carolina, 151B Rutledge Ave, MSC 962, Room B309, Charleston, SC 29425, USA

e-mail: krdeepak2pro@gmail.com

R. B. Souza

Department of Physical Therapy and Rehabilitation Science, University of California-San Francisco, San Francisco, CA, USA
Questions/purposes (1) Do women have higher knee cartilage and meniscus $T_{1 \rho}$ than men in young healthy, middle-aged non-OA and OA populations? (2) Do women exhibit greater static and dynamic (during walking) knee loading than men in young healthy, middle-aged non-OA and OA populations?

Methods Data were collected from three cohorts: (1) young active ( $<35$ years) ( 20 men, 13 women); (2) middleaged ( $\geq 35$ years) without OA (Kellgren-Lawrence $[\mathrm{KL}]$ grade $<2$ ) (43 men, 65 women); and (3) middle-aged with $\mathrm{OA}(\mathrm{KL}>1)$ (18 men, 25 women). $\mathrm{T}_{1 \rho}$ and $\mathrm{T}_{2}$ relaxation times for cartilage in the medial knee, lateral knee, and patellofemoral compartments and medial and lateral menisci were quantified with 3.0-T MRI. A subset of the participants underwent three-dimensional motion capture during walking for calculation of peak knee flexion and adduction moments, flexion and adduction impulses, and peak adduction angle. Differences in MR, radiograph, and gait parameters between men and women were compared in the three groups separately using multivariate analysis of variance.

Results Women had higher lateral articular cartilage $\mathrm{T}_{1 \rho}$ $(\mathrm{men}=40.5[95 \%$ confidence interval $\{\mathrm{CI}\}, 38.8-42.3]$ $\mathrm{ms}$; women $=43.3[95 \% \mathrm{CI}, 41.9-44.7] \mathrm{ms} ; \mathrm{p}=0.017$ )

\section{K. Subburaj}

Engineering Product Development, Singapore University of Technology and Design, Singapore, Singapore

T. D. MacLeod

Department of Physical Therapy, California State University, Sacramento, CA, USA

\section{N. E. Lane}

Center for Musculoskeletal Health, University of California at Davis Medical Center, Sacramento, CA, USA 
and patellofemoral $\mathrm{T}_{1 \rho}(\mathrm{men}=44.4$ [95\% CI, 42.6-46.3] $\mathrm{ms}$; women $=48.4$ [95\% CI, 46.9-50.0] ms; $\mathrm{p}=0.002$ ) in the OA group; and higher lateral meniscus $\mathrm{T}_{1 \rho}$ in the young group $($ men $=15.3[95 \% \mathrm{CI}, 14.7-16.0] \mathrm{ms}$; women $=$ 16.4 [95\% CI, 15.6-17.2] $\mathrm{ms} ; \mathrm{p}=0.045)$. The peak adduction moment in the second half of stance was lower in women in the middle-aged (men $=2.05$ [95\% CI, 1.76-2.34] \%BW*Ht; women = 1.66 [95\% CI, 1.44-1.89] $\left.\% \mathrm{BW}^{*} \mathrm{Ht} ; \mathrm{p}=0.037\right)$ and $\mathrm{OA}(\mathrm{men}=2.34[95 \% \mathrm{CI}$, 1.76-2.91] \%BW*Ht; women = 1.42 [95\% CI, 0.89-1.94] $\% \mathrm{BW}^{*} \mathrm{Ht} ; \mathrm{p}=0.022$ ) groups. Static varus from radiographs was lower in women in the middle-aged $\left(\right.$ men $=178^{\circ}\left[95 \% \mathrm{CI}, 177^{\circ}-179^{\circ}\right]$; women $=180^{\circ}[95 \%$ $\left.\left.\mathrm{CI}, 179^{\circ}-181^{\circ}\right] ; \mathrm{p}=0.002\right)$ and $\mathrm{OA}\left(\operatorname{men}=176^{\circ}[95 \%\right.$ $\left.\mathrm{CI}, 175^{\circ}-178^{\circ}\right]$; women $=180^{\circ} \quad\left[95 \% \mathrm{CI}, 179^{\circ}-181^{\circ}\right]$; $\mathrm{p}<0.001)$ groups. Women had lower varus during walking in all three groups (young: men $=4^{\circ}\left[95 \% \mathrm{CI}, 3^{\circ}-6^{\circ}\right.$; women $=2^{\circ}\left[95 \% \mathrm{CI}, 0^{\circ}-3^{\circ}\right] ; \mathrm{p}=0.013$; middle-aged: men $=2^{\circ}\left[95 \% \mathrm{CI}, 1^{\circ}-3^{\circ}\right]$; women $=0^{\circ}\left[95 \% \mathrm{CI},-1^{\circ}\right.$ to $\left.1^{\circ}\right] ; \mathrm{p}=0.015$; OA: men $=4^{\circ}\left[95 \% \mathrm{CI}, 2^{\circ}-6^{\circ}\right]$; women $=0^{\circ}\left[95 \% \mathrm{CI},-2^{\circ}\right.$ to $\left.\left.2^{\circ}\right] ; \mathrm{p}=0.011\right)$. Women had a higher knee flexion moment $($ men $=4.24[95 \%$ CI, 3.58-4.91] \%BW*Ht; women 5.40 [95\% CI, 4.58-6.21] $\% \mathrm{BW} * \mathrm{Ht} ; \mathrm{p}=0.032$ ) in the young group.

Conclusions These data demonstrate differences in cartilage composition and gait mechanics between men and women in young healthy, middle-aged healthy, and OA cohorts. Considering the cross-sectional nature of the study, longitudinal research is needed to investigate if these differences in cartilage composition and walking mechanics are associated with a greater risk of lateral tibiofemoral or patellofemoral OA in women. Future studies should also investigate the relative risk of lateral versus medial patellofemoral cartilage degeneration risk in women compared with men.

Level of Evidence Level III, retrospective study.

\section{Introduction}

Knee osteoarthritis (OA) is a leading cause of disability in noninstitutionalized adults resulting in significant knee pain and difficulties with activities of daily living [14, 21, 24]. In the United States, approximately 5\% of American adults older than 25 years of age and $12 \%$ older than 65 years of age are affected by knee OA [15, 32]. However, women are at a significantly greater risk of knee OA than men, particularly after 50 years of age $[3,50]$. A systematic review and meta-analysis on published literature on risk factors for onset of knee OA reported a pooled odds ratio of 1.84 (95\% confidence interval [CI], 1.32-2.55) for women compared with men from nine studies that reported effect sizes for sex [3]. However, the reasons for greater risk of knee OA in women are not well understood.

It may be possible that there are differences in cartilage composition between men and women that predispose women to a greater risk of cartilage degeneration, but these differences cannot be found on plain radiographs or anatomic MRI [37, 42]. Quantitative MRI techniques, however, including $T_{1 \rho}$ relaxation time mapping, enable the assessment of cartilage composition noninvasively and are useful to visualize the loss of collagen matrix that occurs early in the OA disease process [1, 33, 44, 45]. An increase in $\mathrm{T}_{1 \rho}$ relaxation times indicates loss of proteoglycans and possibly a concomitant increase in hydration $[1,33,34,38]$. $\mathrm{T}_{1 \rho}$ relaxation times have been shown to detect early knee cartilage degeneration in multiple studies [33, 49, 53, 55].

Another factor that has been shown to be related to the risk of knee OA onset and progression is frontal plane alignment (varus or valgus) [20, 46] and loading at the knee during walking [2]. Varus alignment is associated with a greater risk of medial knee OA and valgus alignment is associated with a greater risk of lateral knee OA $[20,46]$. During walking, the loading in the frontal plane and sagittal plane has been shown to be related to greater risk of onset and progression of knee OA [9, 13, 31, 39]. However, it is not known if there are differences in static and dynamic measures of knee loading that are present between men and women in healthy and OA populations that could be related to greater prevalence of knee OA in women.

The primary objectives of this study were to (1) evaluate whether women have higher knee articular and meniscus cartilage $T_{1 \rho}$ relaxation times when compared with men in young healthy, middle-aged non-OA, and OA populations; and (2) to assess if women exhibit greater static and dynamic (during walking) knee loading compared with men in young healthy, middle-aged non-OA and OA populations, which could explain the sex-related difference in the prevalence of OA. The study hypotheses were that articular cartilage relaxation times, static varus, and gait mechanics will be different between men and women in all three cohorts.

\section{Materials and Methods}

Study Design and Setting

Secondary data analyses from an observational crosssectional study were conducted at the University of 
California-San Francisco, which is a tertiary care medical and research institution.

\section{Participants}

Data reported in this study are secondary analyses from participants recruited from the community for two studies. The first cohort was of "young healthy" volunteers $(\mathrm{n}=33$; men:women $=20: 13$; age $=28 \pm 4$ years; body mass index [BMI], $23 \pm 2 \mathrm{~kg} / \mathrm{m}^{2}$ between the ages of 20 and 35 years who were physically active (at least $150 \mathrm{~min} /$ week of moderate to vigorous physical activity) without any history of knee pain or any other lower extremity injuries that would confound the evaluation of walking patterns. For the second study, participants were recruited for an observational longitudinal study on knee OA. The inclusion criteria for patients with "OA" ( $\mathrm{O}=42$; men: women $=18: 25$; age $=58 \pm 10$ years; BMI, $25 \pm 4$ kg/ $\mathrm{m}^{2}$ ) were age $>35$ years, knee symptoms consistent with OA (pain, aching, or stiffness on most days per month during the past year or use of medication for knee pain on most days per month during the past year), and definite radiographic evidence of knee OA (Kellgren-Lawrence $[\mathrm{KL}]>1)$. The inclusion criteria for "middle-aged nonOA" participants $(\mathrm{n}=108$; men:women $=43: 65$; age $=$ $50 \pm 9$ years; $\quad \mathrm{BMI}=24 \pm 4 \mathrm{~kg} / \mathrm{m}^{2}$ ) were age $>35$ years, no knee pain or stiffness in either knee or use of medications for knee pain in the last year, and no radiographic evidence of $\mathrm{OA}(\mathrm{KL} \leq 1)$ on either knee. The exclusion criteria for all subjects were (1) concurrent use of an investigational drug; (2) history of intraarticular fracture or surgical intervention in the study knee; (3) conditions other than $\mathrm{OA}$ that limit lower extremity function and mobility and/or would confound the evaluation of function; and (4) contraindications to MRI. All subjects signed a written informed consent form before participation in the study, and all protocols were approved by the University of California, San Francisco Committee on Human Research.

\section{Radiographs}

To determine the presence and severity of OA, all middleaged and OA participants underwent bilateral weightbearing and fixed-flexion posteroanterior knee radiographs with the aid of a Synaflexer device (Synarc, Newark, CA, USA) [8]. A radiologist with more than 20 years of experience in musculoskeletal imaging (TML) performed the KL scoring of the tibiofemoral compartment from these radiographs [29]. Lower extremity alignment was assessed by a reader (DK) blinded to subject information using a standing, AP radiograph in which the hips, knees, and ankles were visible. Alignment was determined by the angle (varus $<$ $180^{\circ}$, valgus $>180^{\circ}$ ) of the mechanical axes of the femur and tibia [26]. These data were available from all participants in the middle-aged non-OA and OA groups and a subset of participants from the young healthy group ( $\mathrm{n}=16 ; 10$ men, six women).

\section{MRI Acquisition}

All imaging was performed with 3.0-T GE (General Electric Healthcare, Waukesha, WI, USA) MR scanners (Signa HDx for young subjects, MR 750w for remaining subjects) using an eight-channel phased array transmit/ receive knee coil (Invivo, Orlando, FL, USA). Bilateral knees were imaged for the young group and data from the right knee were used for the analyses in this study. The knee was selected at random by the participants for the middle-aged non-OA group. For the OA group, the knee with worse radiographic severity, or worse symptoms if similar radiographic severity, was imaged. Imaging sequences for segmentation of cartilage regions of interest and quantification of MR relaxation times were acquired (Table 1).

\section{Quantitative MRI Analyses}

Sagittal high-resolution images (spoiled gradient echo or Cube) were rigidly registered to the first image of the $T_{1 \rho}$ sequence (TSL $=0 \mathrm{~ms}$ ) and used for cartilage segmentation. Medial femoral condyle (MF), medial tibia (MT), lateral femoral condyle (LF), lateral tibia (LT), patella (P), Trochlea (TrF), medial meniscus, and lateral meniscus cartilage compartments were segmented semiautomatically (automated edge detection and manual correction) on multiple slices using in-house software program developed with Matlab (Mathworks, Natick, MA, USA) based on edge detection and Bezier splines [6]. $\mathrm{T}_{1 \rho}$ relaxation time maps were constructed by two-parameter fitting of the image intensity (voxel-by-voxel) for four $\mathrm{T}_{1 \rho}$-weighted images using a Levenberg-Marquardt monoexponential fitting algorithm developed in-house: $\mathrm{S}(\mathrm{TSL})=\mathrm{S}_{0}$ $\exp \left(-\mathrm{TSL} / \mathrm{T}_{1 \rho}\right)$, where TSL is the spin lock time and $\mathrm{S}_{0}$ is the signal intensity when $\mathrm{TSL}=0 \mathrm{~ms} ; \mathrm{S}(\mathrm{TE})=\mathrm{S}_{0}$ $\exp \left(-\mathrm{TE} / \mathrm{T}_{2}\right)$. The TSLs used for the fitting were matched for the two studies as closely as possible, ie, $\mathrm{T}_{1 \rho}$ (TSL 0, 10, 40, and $80 \mathrm{~ms}$ for young group; TSL 0, 12, 40, and $80 \mathrm{~ms}$ for remaining subjects). However, for meniscus, only the first three of the mentioned four TSLs for $T_{1 \rho}$ weighted images were used [44]. $\mathrm{T}_{1} \rho_{\text {-weighted images }}$ with the longest TSL had a very low signal-to-noise ratio $(<5)$ for meniscus resulting from short $\mathrm{T}_{1 \rho}$ in meniscus, 
Table 1. MR acquisition parameters for the two studies

\begin{tabular}{|c|c|c|}
\hline Sequence & Parameters & Purpose \\
\hline \multicolumn{3}{|l|}{ For young healthy group } \\
\hline $\begin{array}{l}\text { Sagittal 3-D fat-saturated } \\
\text { high-resolution spoiled } \\
\text { gradient echo }\end{array}$ & $\begin{array}{l}\mathrm{TR} / \mathrm{TE}=15 / 6.7 \mathrm{~ms}, \text { flip angle }=18, \mathrm{FOV}=14 \mathrm{~cm}, \\
\text { matrix }=512 \times 512, \text { slice thickness }=1 \mathrm{~mm}, \text { bandwidth }=31.25 \mathrm{kHz} \text {, } \\
\mathrm{NEX}=1, \text { acquisition time }=8 \text { minutes }\end{array}$ & Cartilage segmentation \\
\hline $\mathrm{T}_{1 \rho}$ quantification sequence & $\begin{array}{l}\mathrm{TSL}=0 / 10 / 40 / 80 \mathrm{~ms} \text {, prep } \mathrm{TE}=0 / 13.7 / 27.3 / 54.7 \mathrm{~ms}, \mathrm{FOV}=14 \mathrm{~cm}, \\
\text { matrix }=256 \times 128, \text { views per segment }(\mathrm{VPS})=64, \text { time of recovery } \\
=1.2 \text { seconds, slice thickness }=4 \mathrm{~mm}, \text { number of } \\
\text { slices }=26, \text { acquisition time }=9 \text { minutes } 30 \text { seconds }\end{array}$ & $\begin{array}{l}\text { Articular and meniscal } \\
\text { cartilage } \mathrm{T}_{1 \rho} \text { relaxation } \\
\text { times }\end{array}$ \\
\hline \multicolumn{3}{|c|}{ For middle-aged control and OA groups } \\
\hline $\begin{array}{l}\text { Sagittal 3-D fat-saturated } \\
\text { fast spin echo Cube }\end{array}$ & $\begin{array}{l}\mathrm{TR} / \mathrm{TE}=1500 / 26.69 \mathrm{~ms}, \mathrm{FOV}=16 \mathrm{~cm}, \text { matrix }=384 \times 384, \text { slice } \\
\text { thickness }=0.5 \mathrm{~mm}, \text { echo train length }=32, \\
\text { bandwidth }=37.5 \mathrm{kHz}, \mathrm{NEX}=0.5, \text { acquisition time }=10.5 \text { minutes }\end{array}$ & Cartilage segmentation \\
\hline $\mathrm{T}_{1 \rho}$ quantification sequence & $\begin{array}{l}\mathrm{TR} / \mathrm{TE}=9 / 2.6 \mathrm{~ms}, \text { time of recovery }=1500 \mathrm{~ms}, \mathrm{FOV}=14 \mathrm{~cm}, \\
\text { matrix }=256 \times 128, \text { slice thickness }=4 \mathrm{~mm}, \text { bandwidth }=62.5 \mathrm{kHz} \text {, } \\
\text { time of spin-lock }(\mathrm{TSL})=0 / 2 / 4 / 8 / 12 / 20 / 40 / 80 \mathrm{~ms}, \\
\text { frequency of spin-lock }=500 \mathrm{~Hz}, \text { acquisition time }=11 \text { minutes }\end{array}$ & $\begin{array}{l}\text { Articular and meniscus } \\
\text { cartilage } \mathrm{T}_{1 \rho} \text { relaxation } \\
\text { times }\end{array}$ \\
\hline
\end{tabular}

3 -D = three-dimensional; FOV $=$ field of view; $\mathrm{NEX}=$ number of excitations; $\mathrm{OA}=$ osteoarthritis.

respectively, and therefore were not used during map reconstruction. The cartilage regions of interest were overlaid onto the $T_{1 \rho}$ maps. The cartilage splines were adjusted manually to avoid synovial fluid or surrounding anatomy. To eliminate artifacts resulting from partial volume effects with synovial fluid, voxels with relaxation time $\geq 100 \mathrm{~ms}$ for cartilage and $\geq 40 \mathrm{~ms}$ for meniscus in the $\mathrm{T}_{1 \rho}$ relaxation time maps were excluded before quantification. These techniques have been shown to be reproducible $[4,5,35]$. Mean $T_{1 \rho}$ values were calculated for three knee articular cartilage compartments: medial knee (mean of MF and MT), lateral knee (mean of LF and LT), and patellofemoral (mean of $\mathrm{P}$ and $\mathrm{TrF}$ ) and for two knee meniscus cartilage compartments: medial meniscus and lateral meniscus.

\section{Walking Gait Analyses}

A subset of the participants underwent walking gait analyses ( $\mathrm{n}=25$ of 33 for young healthy group, $\mathrm{n}=78$ of 109 for middle-aged non-OA group, and $n=29$ of 42 for OA group). The subset consisted of participants who agreed to participate in the motion analysis session. Subjects walked at their self-selected speed while three-dimensional kinematic data were collected at $250 \mathrm{~Hz}$ using a passive 10-camera system (VICON, Oxford Metrics, UK), and kinetic data were collected at $1000 \mathrm{~Hz}$ from two embedded force platforms (AMTI, Watertown, MA, USA). Nine and a half millimeters spherical retroreflective markers were placed on bony landmarks of bilateral lower extremities for identification of joint centers and rigid clusters placed bilaterally on the lateral surface of the subject's thighs, legs, and heel shoe counters were used to track segment motions [48]. A trial was considered acceptable when there was clean foot strike on any of the force platforms and the speed was within $\pm 5 \%$ of the first good trial. At least five good trials were collected from both lower extremities in young subjects and data from the right lower extremity were used in these analyses. For the remaining subjects, data from the extremity that was scanned were used. Kinematic and kinetics were calculated using Visual3D (C-motion, Georgetown, MD, USA). All net joint moments are expressed as external moments $(\mathrm{Nm})$ and normalized to body weight (BW) and height (Ht) $(\% \mathrm{BW} * \mathrm{Ht})$. Variables were calculated for the stance phase when the foot was in contact with the ground and included peak external knee flexion moment, first peak knee adduction moment, second peak knee adduction moment, and peak adduction angle. The average of five trials was calculated for each subject. The first peak of adduction moment and peak varus have been related to medial compartment loading [31]. Additionally, the first peak knee adduction moment has been related to increased risk of medial OA progression [39]. Walking with greater toe-out was found to be related to lower second peak knee adduction moment and a reduced risk of OA progression [7]. Finally, it has been shown that the adduction moment by itself is not sufficient to describe knee loading during walking and the knee flexion moment also contributes to knee loading [52].

\section{Statistical Analyses}

Mean and 95\% CIs were calculated for all outcome measures. Age and BMI were compared between the sexes in each group using independent sample t-tests. Because the outcomes were at the ratio level of measurement, were 
from independent samples, and had homogenous variance, multivariate analysis of variance was used to compare the MRI and gait outcome measures between men and women separately in the three groups. The analyses were repeated with radiographic alignment as a covariate to ascertain the effect of alignment on sex differences in the middle-aged and OA groups. The number of subjects with radiographic alignment data was very low for the young group. Distribution of KL was compared between sexes in the middleaged non-OA and OA groups using chi-square tests. Significance was set at $p<0.05$. Effect size was calculated using the partial eta squared $\left(\eta_{\mathrm{p}}^{2}\right)$ statistic. All analyses were performed using IBM SPSS Version 22 (IBM Corporation, Armonk, NY, USA).

\section{Demographics}

There were no differences in age or BMI (Table 2) between any groups, except women in the young healthy group had lower BMI than the men when all the participants were considered.

\section{Results}

Sex Differences in Articular and Meniscus Cartilage Composition

Women had higher articular cartilage $T_{1 \rho}$ than men in the lateral $\left(p=0.017, \eta_{p}^{2}=0.137\right.$ for $\left.T_{1 \rho}\right)$ and patellofemoral $\left(\mathrm{p}=0.002, \eta_{\mathrm{p}}^{2}=0.227\right.$ for $\left.\mathrm{T}_{1 \rho}\right)$ compartments in the OA group, but not in the other two groups (Fig. 1). There were no significant differences in medial knee cartilage $T_{1 \rho}$ relaxation times between men and women in any of the groups $(p>0.05)$ (Fig. 1). After adjusting for radiographic alignment, the differences in the lateral $T_{1 \rho}$ were no longer statistically significant in the OA group $(\mathrm{p}=0.036)$. However, after adjusting for radiographic alignment, the differences in patellofemoral $T_{1 \rho}$ remained significant $(\mathrm{p}=0.002)$, and the differences in medial $\mathrm{T}_{1 \rho}$ were observed to be significant $(\mathrm{p}=0.036)$ with women having higher $\mathrm{T}_{1 \rho}$.

For the meniscus, lateral meniscus $T_{1 \rho}$ was higher in women in the young healthy group $\left(\mathrm{p}=0.045, \eta_{\mathrm{p}}^{2}=0.140\right)$ (Fig. 2). The medial meniscus $T_{1 \rho}$ was not statistically different between men and women in any group (Fig. 2).

Sex Differences in Static and Dynamic Loading Parameters

In the middle-aged and OA groups, women had a lower second peak knee adduction moment $(\mathrm{p}=0.037$, 


\section{Medial Knee T1p}
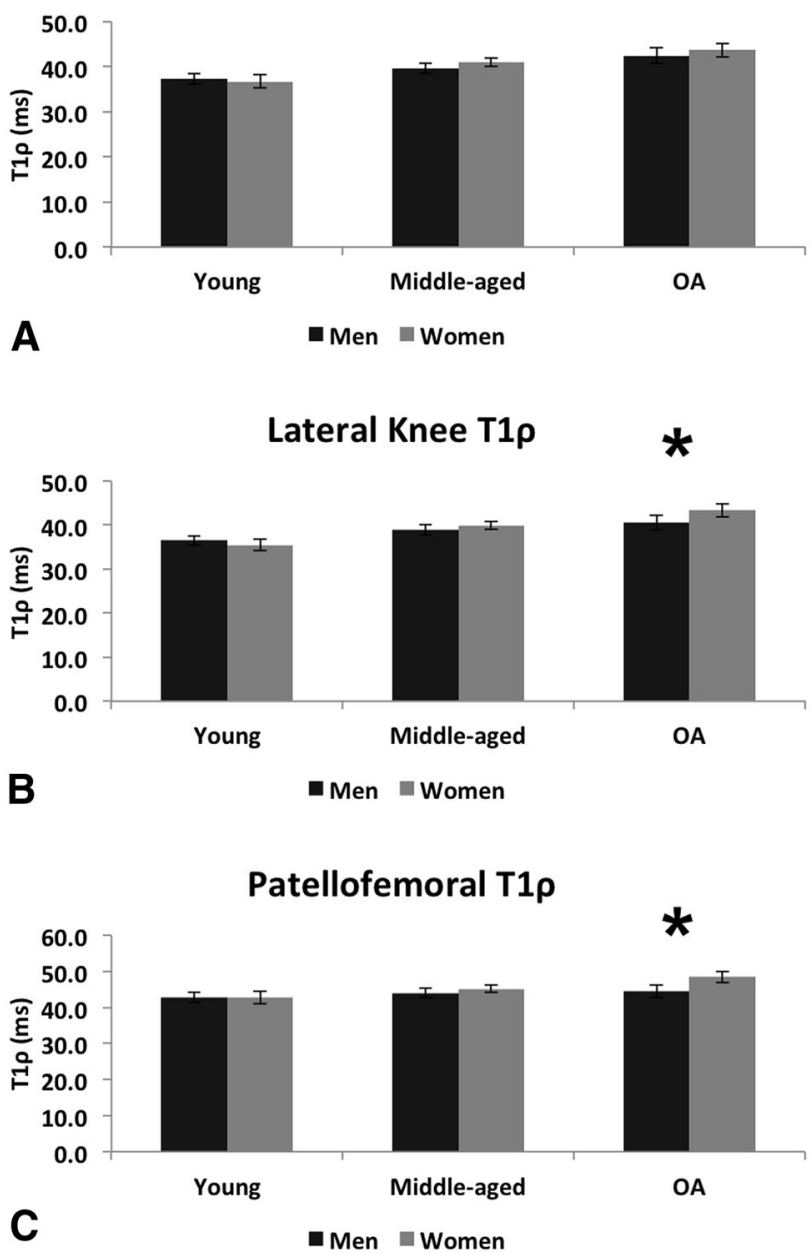

Fig. 1A-C $T_{1 \rho}$ relaxation times for men (black bars) and women (gray bars) are shown for the medial (A), lateral (B), and patellofemoral (C) articular cartilage compartments in the three groups. Error bars indicate $95 \%$ CIs. *Significant differences between men and women at $\mathrm{p}<0.05$.

$\eta_{\mathrm{p}}^{2}=0.056$ for middle-aged group; $\mathrm{p}=0.022, \eta_{\mathrm{p}}^{2}=$ 0.179 for OA group) (Fig. 3). Women also had lower peak varus angle during walking in all three groups $(\mathrm{p}=0.013$, $\eta_{\mathrm{p}}^{2}=0.241$ for young healthy; $\mathrm{p}=0.015, \eta_{\mathrm{p}}^{2}=0.075$ for middle-aged group; $p=0.011, \eta_{p}^{2}=0.216$ for OA group) as well as lower varus angle as measured from radiographs in the middle-aged $\left(\mathrm{p}=0.002, \eta_{\mathrm{p}}^{2}=0.090\right)$ and OA $\left(\mathrm{p}<0.001, \eta_{\mathrm{p}}^{2}=0.278\right)$ groups (Fig. 3 ). The differences in second peak adduction moment and peak varus during walking in the middle-aged and OA groups were not significant after adjusting for radiographic alignment $(p>0.05)$. In the sagittal plane, women had a higher knee flexion moment $\left(\mathrm{p}=0.032, \eta_{\mathrm{p}}^{2}=0.184\right)$ in the young group. The differences in walking speed between men and women were not significant in any of the groups (men $=$

\section{Medial Meniscus T1p}

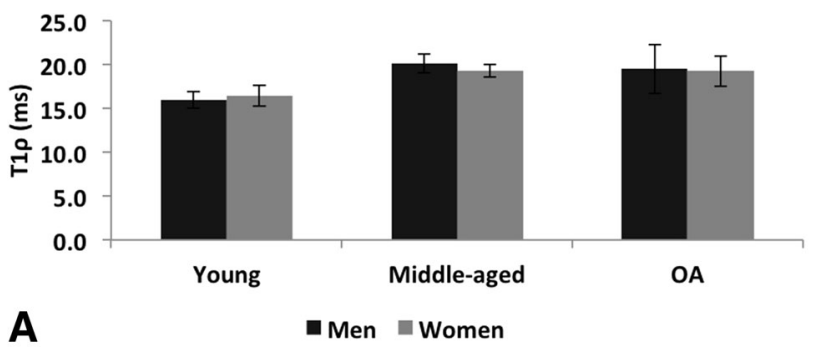

Lateral Meniscus T1p

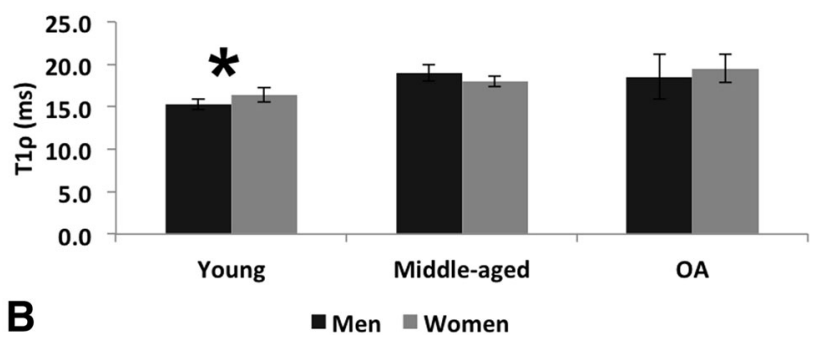

Fig. 2A-B $T_{1 \rho}$ relaxation times for men (black bars) and women (gray bars) are shown for the medial (A) and lateral (B) menisci in the three groups. Error bars indicate 95\% CIs. *Significant differences between men and women at $\mathrm{p}<0.05$.

$1.4 \pm 0.1 \mathrm{~m} / \mathrm{s}$, women $=1.4 \pm 0.2 \mathrm{~m} / \mathrm{s}$ in young healthy; men $=1.6 \pm 0.2 \mathrm{~m} / \mathrm{s}$, women $=1.5 \pm 0.2 \mathrm{~m} / \mathrm{s}$ in middleaged group; men $=1.5 \pm 0.2 \mathrm{~m} / \mathrm{s}$, women $=1.5 \pm 0.3 \mathrm{~m} / \mathrm{s}$ in OA group) (Fig. 3).

\section{Discussion}

Women have a significantly greater risk of knee OA than men, especially with increasing age. However, the reasons for greater risk of knee OA in women are not well understood. Walking mechanics are implicated in the pathogenesis of cartilage degeneration in OA. Hence, it may be possible that there are differences in cartilage composition and walking mechanics between men and women that predispose women to a greater risk of OA. The objective of this study was to evaluate the differences in knee cartilage MR relaxation times, and static and dynamic measures of knee loading, between men and women in young healthy, middle-aged healthy, and OA populations. Our results show that women have higher MR relaxation times in the lateral and patellofemoral compartments in the OA group and women have lower second peak adduction moment in the middle-aged and OA groups. Women also had lower static and dynamic varus in the middle-aged and OA groups and lower varus during walking in all groups.

The study has several limitations that need to be considered while interpreting the findings. The sample size in 
First Peak Knee Adduction Moment

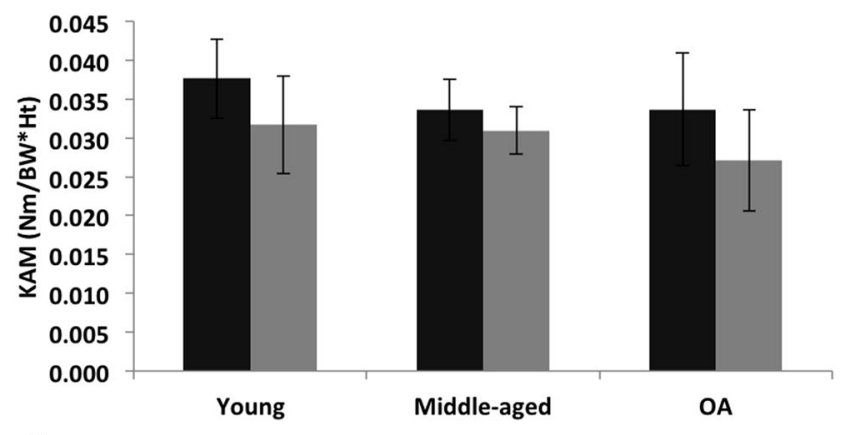

A

men Women

Second Peak Knee Adduction Moment

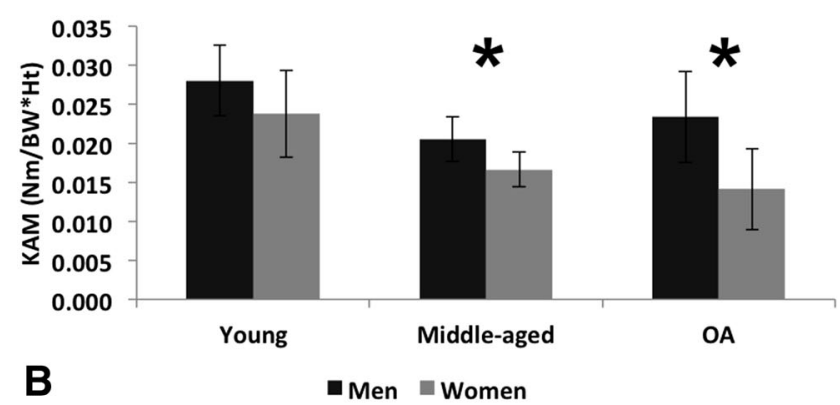

Peak Flexion Moment

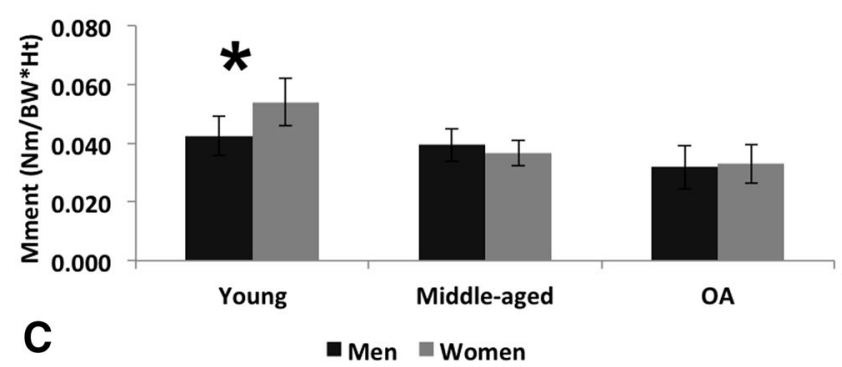

Fig. 3A-E First and second peak adduction moment (A-B), flexion moment $(\mathbf{C})$, peak varus during walking $(\mathbf{D})$, and static varus from radiograph (E) are shown for men (black bars) and women (gray bars)

the young healthy and OA groups was relatively small, especially for biomechanical parameters; and the number of men and women was not balanced in each group. Hence, these findings would need to be replicated in larger populations. Because these results are from secondary analyses of existing data, we used all existing data to maximize the sample size. Additionally, the cross-sectional nature of the study allowed for the detection of an association, but we cannot infer causality from this study or make interpretations about associations of these outcomes with risk of knee OA. Longitudinal studies are needed to investigate if there are sex differences in cartilage composition and walking mechanics in these populations over time. Earlier studies have reported radiographic joint space
Peak Varus during Walking
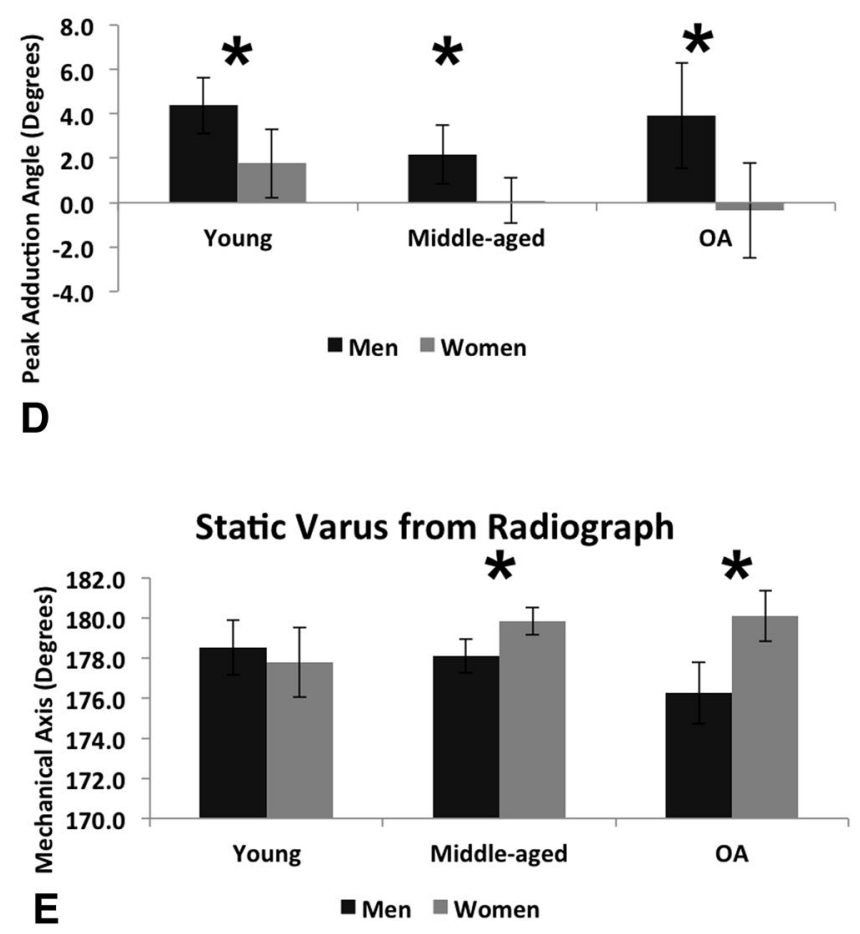

in the three groups. Error bars indicate 95\% CIs. *Significant differences between men and women at $\mathrm{p}<0.05$.

width. We report KL scores and quantitative MR imaging data. Quantitative MR data provide evidence of early cartilage degeneration that may not be visualized using radiographic joint space width measurements. The use of different imaging sequence in the young group versus the middle-aged and OA groups did not allow comparison of MR parameters among the three cohorts. However, the goal of this study was to evaluate the differences between men and women in the three groups. Also, we did not make adjustments for multiple comparisons; therefore, $\mathrm{p}$ values close to 0.05 should be interpreted with caution.

We observed that women in the OA group had higher articular cartilage $\mathrm{T}_{1 \rho}$ in the lateral compartment compared with men. These differences had medium to large effect 
sizes in our cohort. Higher $\mathrm{T}_{1 \rho}$ indicates worse cartilage composition with lower proteoglycan content. Wise et al. [54] reported that women have a greater prevalence of joint space narrowing in the lateral compartment than men in a sample of 5202 knees of people with and without knee OA from the Multi-center Osteoarthritis Study (MOST). Our MRI findings partially support this observation with higher $\mathrm{T}_{1 \rho}$ in the lateral compartment in the OA group but not in the middle-aged group that did not have radiographic OA. Use of quantitative MR imaging allows us to observe the cartilage degeneration while controlling for the presence of radiographic OA. This is important considering the fact that interventions to prevent the onset of OA are likely to be more effective before radiographic changes have occurred. Furthermore, it has been shown that MR relaxation measures of cartilage predict future progression of OA [36, 43]. Wise et al. [54] also reported that women have greater prevalence of valgus alignment, which was also seen in our cohorts. After adjusting for lower extremity alignment, Wise et al. found that the prevalence of lateral joint space narrowing between women and men was no longer significant, and women had a greater prevalence of medial joint space narrowing. We observed similar results in that the differences in lateral articular cartilage $T_{1 \rho}$ were no longer statistically significant after adjusting for radiographic alignment, whereas the differences in medial $T_{1 \rho}$ became significant. These results indicate that greater degeneration of the lateral compartment in women may be partially related to more valgus alignment of the lower extremity in women, whereas the differences in the medial compartment may be related to other factors. However, longitudinal studies are needed to confirm these observations.

We also observed greater $T_{1 \rho}$ in the patellofemoral articular cartilage in women compared with men in the OA group. These differences were significant even after adjusting for radiographic alignment. Wise et al. [54] did not report data on patellofemoral compartment in their study. However, using MOST data, Glass et al. [22] recently reported that women have a greater prevalence of patellofemoral OA than men. Furthermore, in knees with patellofemoral OA, women reported greater severity of pain for all KL grades than men. The authors speculated that the mechanisms underlying tibiofemoral OA may be different from those underlying patellofemoral OA, as has been suggested in other studies [12, 25]. Our data support these observations because lower extremity alignment affected the differences in tibiofemoral cartilage $T_{1 \rho}$ but not the differences in patellofemoral cartilage $T_{1 \rho}$. One anatomic factor that has been shown to be related to patellofemoral OA that we did not evaluate in our study is trochlear dysplasia [28]. Furthermore, it may be possible that the interaction of sex and alignment may be different for medial and lateral patellofemoral compartments, although recent studies have not reported it [23]. In this study, we did not evaluate medial and lateral patellofemoral compartments separately. Hence, future work needs to consider trochlear dysplasia and other factors that may be related to higher patellofemoral $T_{1 \rho}$ in women and differences in medial and lateral patellofemoral compartments.

We did not find a significant difference between sexes in articular cartilage composition in the young and middleaged groups. A vast majority of earlier studies on sex differences in knee cartilage have focused on cartilage thickness and volume and have reported lower cartilage volume and thickness in women compared with men in healthy young and older individuals without knee OA [11, $16,18,19,41]$. However, it is not known if thicker cartilage by itself is protective against knee OA [17]. One study specifically studied sex differences in articular cartilage $\mathrm{T}_{2}$ in young healthy adults (20-29 years) and did not observe any significant difference [40]. Our results are in agreement with theirs because we did not observe significant differences in cartilage composition between men and women in the young healthy and middle-aged non-OA groups. Further studies are needed on sex differences in articular cartilage composition from larger longitudinal cohorts like the Osteoarthritis Initiative.

For the meniscus, we did not observe statistically significant differences between men and women in any group except for higher lateral meniscus $T_{1 \rho}$ was higher in women in the young healthy group. There are two published reports of sex differences in meniscus composition from the one research group $[10,51]$. They reported higher $\mathrm{T}_{2}$ for the posterior horn of the medial meniscus in women compared with men irrespective of the age. In our cohort, the difference for medial posterior horn was also not significant for any group (results not shown). The authors in the previous studies speculated that the difference in meniscus composition was related to walking mechanics. However, we observed less medial loading in women compared with men as would be expected with the greater valgus alignment. It may be possible that women have greater loading over the lateral compartment during walking, although it is not possible to confirm this from the data in this study.

We observed differences in gait biomechanics characterized by lower second peak knee adduction moment and lower varus during walking in women compared with men. Another study reported lower knee adduction moment in women compared with men with knee OA [47], similar to our findings. These data suggest that women may experience lower loading over the medial compartment than men. Further evidence comes from the well-established observation of greater valgus alignment in women [54] as was 
also seen in our cohorts. However, the differences in the first peak knee adduction moment were not significant. A reduction in the second peak knee adduction moment has been associated with a reduced risk of OA progression, and there have been studies on gait retraining interventions to reduce the second peak knee adduction moment [7, 27]. We also did not observe significant differences in medial cartilage or meniscus $T_{1 \rho}$ in any of the groups. Hence, further research is needed to assess if a lower second peak knee adduction moment but not first peak knee adduction moment leads to lower medial loading in women compared with men.

The differences in adduction moment and peak varus during walking were not significant after adjusting for the radiographic alignment suggesting that lower extremity alignment may be a key factor related to differences in gait mechanics between men and women. It is not possible to directly estimate lateral compartment loading from these data. However, it may be possible that observed differences in lateral $T_{1 \rho}$ may be related to mechanical factors. Previous studies in gait mechanics that explored sex differences report higher knee flexion moment in preswing in healthy young women compared with men [30]. In this earlier study, women were observed to have higher knee flexion moment in early stance as well but the difference was not significant. We did observe a greater peak flexion moment in women in early stance compared with men. The difference could be the result of populations or the difference in joint moment normalization (body mass and height versus body weight and height). Longitudinal studies are needed to investigate the effect of differences in gait mechanics between sexes on the risk of OA incidence and progression.

In conclusion, we observed that women with radiographic knee OA had higher lateral and patellofemoral compartment MR relaxation times compared with men indicating deterioration in cartilage composition. We also observed significantly higher varus and lower second peak adduction moment in women compared with men. These data demonstrate differences in cartilage composition and gait mechanics between men and women in young healthy, middle-aged healthy, and OA cohorts. Future longitudinal studies are needed to investigate if these differences in cartilage composition and walking mechanics are associated with a greater risk of lateral tibiofemoral or patellofemoral OA in women. Future studies should also investigate the relative risk of lateral versus medial patellofemoral cartilage degeneration risk in women compared with men.

Acknowledgments We thank Anthony Luke for providing equipment and facilities for motion capture and Joseph Schooler, Nishant Neel, and Kelly Bauer for data processing.

\section{References}

1. Akella SV, Regatte RR, Gougoutas AJ, Borthakur A, Shapiro EM, Kneeland JB, Leigh JS, Reddy R. Proteoglycan-induced changes in T1rho-relaxation of articular cartilage at 4T. Magn Reson Med. 2001;46:419-423.

2. Andriacchi TP, Mundermann A. The role of ambulatory mechanics in the initiation and progression of knee osteoarthritis. Curr Opin Rheumatol. 2006;18:514-518.

3. Blagojevic M, Jinks C, Jeffery A, Jordan KP. Risk factors for onset of osteoarthritis of the knee in older adults: a systematic review and meta-analysis. Osteoarthritis Cartilage. 2010;18: 24-33.

4. Blumenkrantz G, Lindsey CT, Dunn TC, Jin H, Ries MD, Link TM, Steinbach LS, Majumdar S. A pilot, two-year longitudinal study of the interrelationship between trabecular bone and articular cartilage in the osteoarthritic knee. Osteoarthritis Cartilage. 2004;12:997-1005.

5. Bolbos RI, Link TM, Ma CB, Majumdar S, Li X. T1rho relaxation time of the meniscus and its relationship with T1rho of adjacent cartilage in knees with acute ACL injuries at $3 \mathrm{~T}$. Osteoarthritis Cartilage. 2009;17:12-18.

6. Carballido-Gamio J, Bauer JS, Stahl R, Lee KY, Krause S, Link TM, Majumdar S. Inter-subject comparison of MRI knee cartilage thickness. Med Image Anal. 2008;12:120-135.

7. Chang A, Hurwitz D, Dunlop D, Song J, Cahue S, Hayes K, Sharma $\mathrm{L}$. The relationship between toe-out angle during gait and progression of medial tibiofemoral osteoarthritis. Ann Rheum Dis. 2007;66:1271-1275.

8. Charles HC, Kraus VB, Ainslie M, Hellio Le Graverand-Gastineau MP. Optimization of the fixed-flexion knee radiograph. Osteoarthritis Cartilage. 2007;15:1221-1224.

9. Chehab EF, Favre J, Erhart-Hledik JC, Andriacchi TP. Baseline knee adduction and flexion moments during walking are both associated with 5 year cartilage changes in patients with medial knee osteoarthritis. Osteoarthritis Cartilage. 2014;22:1833-1839.

10. Chiang SW, Tsai PH, Chang YC, Wang CY, Chung HW, Lee HS, Chou MC, Hsu YC, Huang GS. T2 values of posterior horns of knee menisci in asymptomatic subjects. PloS One. 2013;8: e59769.

11. Cicuttini F, Forbes A, Morris K, Darling S, Bailey M, Stuckey S. Gender differences in knee cartilage volume as measured by magnetic resonance imaging. Osteoarthritis Cartilage. 1999;7: 265-271.

12. Cicuttini FM, Spector T, Baker J. Risk factors for osteoarthritis in the tibiofemoral and patellofemoral joints of the knee. J Rheumatol. 1997;24:1164-1167.

13. Creaby MW, Hunt MA, Hinman RS, Bennell KL. Sagittal plane joint loading is related to knee flexion in osteoarthritic gait. Clin Biomech (Bristol, Avon). 2013;28:916-920.

14. Dekker J, van Dijk GM, Veenhof C. Risk factors for functional decline in osteoarthritis of the hip or knee. Curr Opin Rheumatol. 2009;21:520-524.

15. Dillon CF, Hirsch R, Rasch EK, Gu Q. Symptomatic hand osteoarthritis in the United States: prevalence and functional impairment estimates from the third US National Health and Nutrition Examination Survey, 1991-1994. Am J Phys Med Rehabil. 2007;86:12-21.

16. Ding C, Cicuttini F, Scott F, Glisson M, Jones G. Sex differences in knee cartilage volume in adults: role of body and bone size, age and physical activity. Rheumatology. 2003;42:1317-1323.

17. Eckstein F, Siedek V, Glaser C, Al-Ali D, Englmeier KH, Reiser $\mathrm{M}$, Graichen $\mathrm{H}$. Correlation and sex differences between ankle and knee cartilage morphology determined by quantitative magnetic resonance imaging. Ann Rheum Dis. 2004;63:1490-1495. 
18. Eckstein F, Yang M, Guermazi A, Roemer FW, Hudelmaier M, Picha K, Baribaud F, Wirth W, Felson DT. Reference values and Z-scores for subregional femorotibial cartilage thickness-results from a large population-based sample (Framingham) and comparison with the non-exposed Osteoarthritis Initiative reference cohort. Osteoarthritis Cartilage. 2010;18:1275-1283.

19. Faber SC, Eckstein F, Lukasz S, Muhlbauer R, Hohe J, Englmeier $\mathrm{KH}$, Reiser M. Gender differences in knee joint cartilage thickness, volume and articular surface areas: assessment with quantitative three-dimensional MR imaging. Skeletal Radiol. 2001;30: 144-150.

20. Felson DT, Niu J, Gross KD, Englund M, Sharma L, Cooke TD, Guermazi A, Roemer FW, Segal N, Goggins JM, Lewis CE, Eaton C, Nevitt MC. Valgus malalignment is a risk factor for lateral knee osteoarthritis incidence and progression: findings from the Multicenter Osteoarthritis Study and the Osteoarthritis Initiative. Arthritis Rheum. 2013;65:355-362.

21. Fitzgerald GK, Piva SR, Irrgang JJ. Reports of joint instability in knee osteoarthritis: its prevalence and relationship to physical function. Arthritis Rheum. 2004;51:941-946.

22. Glass N, Segal NA, Sluka KA, Torner JC, Nevitt MC, Felson DT, Bradley LA, Neogi T, Lewis CE, Frey-Law LA. Examining sex differences in knee pain: the Multicenter Osteoarthritis Study. Osteoarthritis Cartilage. 2014;22:1100-1106.

23. Gross KD, Niu J, Stefanik JJ, Guermazi A, Roemer FW, Sharma L, Nevitt MC, Segal NA, Lewis CE, Felson DT. Breaking the Law of Valgus: the surprising and unexplained prevalence of medial patellofemoral cartilage damage. Ann Rheum Dis. 2012;71: $1827-1832$.

24. Guccione AA, Felson DT, Anderson JJ, Anthony JM, Zhang Y, Wilson PW, Kelly-Hayes M, Wolf PA, Kreger BE, Kannel WB. The effects of specific medical conditions on the functional limitations of elders in the Framingham Study. Am J Public Health. 1994;84:351-358.

25. Hinman RS, Crossley KM. Patellofemoral joint osteoarthritis: an important subgroup of knee osteoarthritis. Rheumatology. 2007;46: 1057-1062.

26. Hsu RW, Himeno S, Coventry MB, Chao EY. Normal axial alignment of the lower extremity and load-bearing distribution at the knee. Clin Orthop Relat Res. 1990;255:215-227.

27. Hunt MA, Takacs J. Effects of a 10-week toe-out gait modification intervention in people with medial knee osteoarthritis: a pilot, feasibility study. Osteoarthritis Cartilage. 2014;22:904-911.

28. Jungmann PM, Tham SC, Liebl H, Nevitt MC, McCulloch CE, Lynch J, Link TM. Association of trochlear dysplasia with degenerative abnormalities in the knee: data from the Osteoarthritis Initiative. Skeletal Radiol. 2013;42:1383-1392.

29. Kellgren JH, Lawrence JS. Radiological assessment of osteoarthrosis. Ann Rheum Dis. 1957;16:494-502.

30. Kerrigan DC, Todd MK, Della Croce U. Gender differences in joint biomechanics during walking: normative study in young adults. Am J Phys Med Rehabil. 1998;77:2-7.

31. Kumar D, Manal KT, Rudolph KS. Knee joint loading during gait in healthy controls and individuals with knee osteoarthritis. Osteoarthritis Cartilage. 2013;21:298-305.

32. Lawrence RC, Felson DT, Helmick CG, Arnold LM, Choi H, Deyo RA, Gabriel S, Hirsch R, Hochberg MC, Hunder GG, Jordan JM, Katz JN, Kremers HM, Wolfe F. Estimates of the prevalence of arthritis and other rheumatic conditions in the United States. Part II. Arthritis Rheum. 2008;58:26-35.

33. Li X, Benjamin Ma C, Link TM, Castillo DD, Blumenkrantz G, Lozano J, Carballido-Gamio J, Ries M, Majumdar S. In vivo $\mathrm{T}$ (1rho) and $\mathrm{T}(2)$ mapping of articular cartilage in osteoarthritis of the knee using 3 T MRI. Osteoarthritis Cartilage. 2007;15: 789-797.
34. Li X, Cheng J, Lin K, Saadat E, Bolbos RI, Jobke B, Ries MD, Horvai A, Link TM, Majumdar S. Quantitative MRI using T1rho and T2 in human osteoarthritic cartilage specimens: correlation with biochemical measurements and histology. Magn Reson Imaging. 2011;29:324-334.

35. Li X, Wyatt C, Rivoire J, Han E, Chen W, Schooler J, Liang F, Shet K, Souza R, Majumdar S. Simultaneous acquisition of T1rho and $\mathrm{T} 2$ quantification in knee cartilage: repeatability and diurnal variation. J Magn Reson Imaging. 2014;39:1287-1293.

36. Liebl H, Joseph G, Nevitt MC, Singh N, Heilmeier U, Subburaj K, Jungmann PM, McCulloch CE, Lynch JA, Lane NE, Link TM. Early T2 changes predict onset of radiographic knee osteoarthritis: data from the Osteoarthritis Initiative. Ann Rheum Dis. 2014 Mar 10 [Epub ahead of print].

37. Lohmander LS. Articular cartilage and osteoarthrosis. The role of molecular markers to monitor breakdown, repair and disease. J Anat. 1994;184:477-492.

38. Menezes NM, Gray ML, Hartke JR, Burstein D. T2 and T1rho MRI in articular cartilage systems. Magn Reson Med. 2004;51: 503-509.

39. Miyazaki T, Wada M, Kawahara H, Sato M, Baba H, Shimada S. Dynamic load at baseline can predict radiographic disease progression in medial compartment knee osteoarthritis. Ann Rheum Dis. 2002;61:617-622.

40. Mosher TJ, Collins CM, Smith HE, Moser LE, Sivarajah RT, Dardzinski BJ, Smith MB. Effect of gender on in vivo cartilage magnetic resonance imaging T2 mapping. J Magn Reson Imaging. 2004;19:323-328.

41. Otterness IG, Eckstein F. Women have thinner cartilage and smaller joint surfaces than men after adjustment for body height and weight. Osteoarthritis Cartilage. 2007;15:666-672.

42. Pearle AD, Warren RF, Rodeo SA. Basic science of articular cartilage and osteoarthritis. Clin Sports Med. 2005;24:1-12.

43. Prasad AP, Nardo L, Schooler J, Joseph GB, Link TM. T(1)rho and $\mathrm{T}(2)$ relaxation times predict progression of knee osteoarthritis. Osteoarthritis Cartilage. 2013;21:69-76.

44. Rauscher I, Stahl R, Cheng J, Li X, Huber MB, Luke A, Majumdar $\mathrm{S}$, Link TM. Meniscal measurements of T1rho and T2 at MR imaging in healthy subjects and patients with osteoarthritis. Radiology. 2008;249:591-600.

45. Regatte RR, Akella SV, Lonner JH, Kneeland JB, Reddy R. T1rho relaxation mapping in human osteoarthritis (OA) cartilage: comparison of T1rho with T2. J Magn Reson Imaging. 2006;23: $547-553$

46. Sharma L, Chmiel JS, Almagor O, Felson D, Guermazi A, Roemer F, Lewis CE, Segal N, Torner J, Cooke TD, Hietpas J, Lynch J, Nevitt M. The role of varus and valgus alignment in the initial development of knee cartilage damage by MRI: the MOST study. Ann Rheum Dis. 2013;72:235-240.

47. Sims EL, Carland JM, Keefe FJ, Kraus VB, Guilak F, Schmitt D. Sex differences in biomechanics associated with knee osteoarthritis. J Women Aging. 2009;21:159-170.

48. Souza RB, Fang C, Luke A, Wu S, Li X, Majumdar S. Relationship between knee kinetics during jumping tasks and knee articular cartilage MRI T1rho and T2 relaxation times. Clin Biomech (Bristol, Avon). 2012;27:403-408.

49. Souza RB, Feeley BT, Zarins ZA, Link TM, Li X, Majumdar S. T1rho MRI relaxation in knee OA subjects with varying sizes of cartilage lesions. Knee. 2013;20:113-119.

50. Srikanth VK, Fryer JL, Zhai G, Winzenberg TM, Hosmer D, Jones G. A meta-analysis of sex differences prevalence, incidence and severity of osteoarthritis. Osteoarthritis Cartilage. 2005;13: 769-781.

51. Tsai PH, Chou MC, Lee HS, Lee CH, Chung HW, Chang YC, Huang GS. MR T2 values of the knee menisci in the healthy young 
population: zonal and sex differences. Osteoarthritis Cartilage. 2009;17:988-994.

52. Walter JP, D'Lima DD, Colwell CW, Jr., Fregly BJ. Decreased knee adduction moment does not guarantee decreased medial contact force during gait. J Orthop Res. 2010;28:1348-1354.

53. Wang L, Chang G, Xu J, Vieira RL, Krasnokutsky S, Abramson S, Regatte RR. T1rho MRI of menisci and cartilage in patients with osteoarthritis at 3T. Eur J Radiol. 2012;81:2329-2336.

54. Wise BL, Niu J, Yang M, Lane NE, Harvey W, Felson DT, Hietpas J, Nevitt M, Sharma L, Torner J, Lewis CE, Zhang Y,
Multicenter Osteoarthritis Group. Patterns of compartment involvement in tibiofemoral osteoarthritis in men and women and in whites and African Americans. Arthritis Care Res. 2012;64: $847-852$.

55. Zarins ZA, Bolbos RI, Pialat JB, Link TM, Li X, Souza RB, Majumdar S. Cartilage and meniscus assessment using T1rho and T2 measurements in healthy subjects and patients with osteoarthritis. Osteoarthritis Cartilage. 2010;18:1408-1416. 